\title{
ASSESSMENT OF MANUAL DYSFUNCTION IN OCCUPATIONALLY ACTIVE WOMEN WITH CARPAL TUNNEL SYNDROME
}

\section{TOMASZ WOLNY, PAWEL LINEK, and EDWARD SAULICZ}

The Jerzy Kukuczka Academy of Physical Education in Katowice, Katowice, Poland

Department of Kinesitherapy and Special Methods in Physiotherapy

\begin{abstract}
Objectives: The aim of this study is to evaluate 2-point discrimination sense (2PD), strength and kinesthetic differentiation of strength (KDS), range of motion (ROM) and kinesthetic differentiation of movement (KDM) dysfunctions in occupationally active women with mild and moderate forms of carpal tunnel syndrome (CTS) compared to a healthy group. Material and Methods: The 2PD sense, muscle strength and KDS, as well as the ROM and KDM of the radiocarpal articulation were assessed. Results: The results of the 2PD sense assessment showed significantly higher values in all the examined fingers in the CTS women group compared to healthy women $(\mathrm{p}<0.01)$. There was a significant difference in the percentage value of error in the strength and KDS of pincer and cylindrical grips $(\mathrm{p}<0.01)$ in the CTS women group compared to healthy women. There was no difference in the ROM of flexion and extension between studied groups $(\mathrm{p}>0.05)$. There was a significant difference in the percentage value of error in the KDM of flexion and extension movement of the radiocarpal articulation $(\mathrm{p}<0.01)$ between the studied groups. Conclusions: There are significant differences in the 2PD sense, KDS and KDM in occupationally active women with mild and moderate forms of CTS compared to healthy women. There are no significant differences in ROM in professionally active women with mild and moderate forms of CTS compared to healthy women. Int J Occup Med Environ Health. 2019;32(2):185-96
\end{abstract}

Key words:

occupational health, strength, range of motion, carpal tunnel syndrome, 2-point discrimination sense, kinesthetic differentiation

\section{INTRODUCTION}

Carpal tunnel syndrome (CTS) is the most common compression mononeuropathy [1,2] and one of the most common conditions in the working age [3]. The incidence of CTS, as evaluated by a number of authors, varies from $1.5 \%$ to $3.8 \%$ in the general population [3-5], but for some occupations, this increases to $15-78 \%[6,7]$. The CTS problem is 3 times as common among women as among men [8], where the annual incidence is estimated at 139 cases per 100000 women [9]. According to Bongers et al. [10] the incidence of CTS in women is 280/100 000 women annually. These figures indicate that CTS is a widespread problem among women and that the average age of diagnosed women is 50 years [11]. Thus, it is a problem for many women of working age.

Bonfiglioli et al. [12] indicate that the relationship between occupational exposure and the risk of CTS is based on strong scientific evidence. The occupational factors that may contribute to the development of CTS, described by various authors, include performing stereotypic, repetitive hand movements, heavy upper extremity workload, forced and uncomfortable working position and vibration

Received: September 7, 2017. Accepted: June 15, 2018.

Corresponding author: Paweł Linek, The Jerzy Kukuczka Academy of Physical Education in Katowice, Department of Kinesitherapy and Special Methods in Physiotherapy, Mikołowska 72B, 40-065 Katowice, Poland (e-mail: linek.fizjoterapia@vp.pl). 
[13-16]. Tests of grip strength and frequency of hand movement repetitions in employees representing 39 various occupations have shown that occupation is a risk factor only when it includes using high grip strength combined with high repetition of a given activity [14]. This work also demonstrates that muscle strength is a smaller risk factor for CTS than the repetition of a specific activity [14]. However, in another study, Chiang et al. [17] indicate that hand grip strength is a stronger risk factor for CTS development than the frequency of motions. It appears, however, that intensive hand activity is a relevant factor, which increases the incidence of CTS, as many occupations related to intensive hand activity yield CTS diagnoses - ski manufacturing workers $(15 \%)$ [6], grocery store workers (23\%) [18], supermarket checkers (62\%) [19], meat processing workers $(23 \%)$ [20,21], carpenters $(78 \%)$ [7], floor cleaners (48\%) [22].

McDiarmid et al. [23] also report that CTS is 3 times more common among women as compared to men. Some authors even point to the female gender as a risk factor for CTS [12,19,23]. It appears, however, that the main cause of CTS among women is that they perform activities which simply increase the risk of CTS [23]. In fact, women are more likely to have a higher risk of CTS, as they are more likely (than men) to perform certain occupations. Studies show that $98.4 \%$ of dental hygienists, $94.3 \%$ of typists, $93.4 \%$ of dressmakers, $89.6 \%$ of hairdressers and cosmetologists, and $89.6 \%$ of accountants are women, and these occupations are among the high-risk groups for CTS [23]. Other studies also show that even if a woman performs an occupation that does not belong to the group of high-risk occupations, women perform a much wider variety of activities which pose a greater risk of developing CTS during their work [24].

Regardless of whether the causes of increased CTS risk among women depend on the type of work performed, gender, disease incidence (diabetes, obesity, hormonal disorders, etc.), the symptoms that appear daily and gradually worsen must affect the occupational and non-occupational activi- ties of the day. Disorders of diverse sensation types [25-27], pain $[28,29]$, impairment of hand function [27,29], reduction of strength of the muscles responsible for functional efficiency of the hand and thus, reduction of strength of several grip types [27,30] in women diagnosed with CTS have been indicated in numerous scientific papers.

Carpal tunnel syndrome also affects overall health status, both in its physical and mental components [31]. Undoubtedly, the local symptoms associated with an affected hand or hands, which affect manual functioning, but also the global ones that impair the general sense of health, have an impact on occupational activity and therefore on deteriorating productivity and efficiency of work, which obviously has economic and social consequences [12,21]. The authors have not found any research so far to evaluate the effects of various sensory disorders, muscle strength and the range of mobility, concerning the hands of occupationally active women who have developed CTS and whose work requires an elevated level of hand engagement.

We believe that the impairment of the distinct sensation types may result in a gnosis disorder, which manifests itself in a difficulty in recognizing objects by touch. The consequence of kinesthetic sense disorder may be a decrease in the precision of movement and an impairment of precision grips. Impairment of the sensory function may also increase the risk of injury during work. The decrease in the strength of the muscles responsible for hand function may result in a deterioration of grip strength. Limiting the range of mobility may also cause an impairment of hand function during occupational activities. These disorders, which may develop in the hands of occupationally active women with CTS, may on one hand result in the impairment of work comfort and, on the other hand, affect the quality and productivity of work. It is therefore important to detect the developing disorders early, so that one can quickly take the right therapy and prevent the symptoms from increasing. Therefore, the main purpose of this study is to assess the manual dysfunction of hands in occupationally active women with mild and moderate CTS. 


\section{MATERIAL AND METHODS}

\section{Ethics}

This study was authorized by the Bioethics Committee for Scientific Studies at The Jerzy Kukuczka Academy of Physical Education in Katowice on 31 May 2007 (Decision No. 16/2007). All study procedures were performed according to the Helsinki Declaration of Human Rights of 1975, modified in 1983.

\section{Study design}

This was a case-control study conducted in the southern part of Poland. Professionally active women with CTS were selected from some medical outpatient clinics in 2015-2016 and were included in the case group. Professionally active women in the control group were randomly selected from different workplaces in the same region. Due to the nature of their work, the women were divided into 3 groups: white-collar worker, pink-collar worker and blue-collar worker [25]. This division was used due to the fact that it was difficult to collect a representative group of women with CTS executing exactly the same tasks. All participants were informed about what the study would involve and told that they could withdraw without giving a reason. Written informed consent was obtained from all participants.

\section{Participants}

In total, 312 professionally active women were examined including 157 with mild and moderate forms of CTS and 155 healthy controls. Participants in the study were women who mostly used their hands during work. The characteristics of the respondents and the results of testing the homogeneity of the groups are presented in the Table 1.

\section{Diagnostic criteria}

Inclusion criteria for professionally active women with CTS in the case group were:

- CTS diagnosed by a physician;

Table 1. Characteristics of the participants of the study on manual dysfunction in occupationally active women from southern Poland in 2015-2016

\begin{tabular}{|c|c|c|c|c|c|c|c|}
\hline \multirow{3}{*}{ Characteristics } & \multicolumn{4}{|c|}{ Respondents } & \multirow{3}{*}{ Difference } & \multirow{3}{*}{$95 \% \mathrm{CI}$} & \multirow{3}{*}{$\begin{array}{c}\text { Significance } \\
\text { level }\end{array}$} \\
\hline & \multicolumn{2}{|c|}{$\begin{array}{c}\text { CTS } \\
(\mathrm{N}=157)\end{array}$} & \multicolumn{2}{|c|}{$\begin{array}{c}\text { control } \\
(\mathrm{N}=155)\end{array}$} & & & \\
\hline & $\mathrm{M} \pm \mathrm{SD}$ & $\min .-\max$ & $\mathrm{M} \pm \mathrm{SD}$ & $\min .-\max$ & & & \\
\hline Age [years] & $50.5 \pm 6.64$ & $26-58$ & $49.6 \pm 6.17$ & $35-58$ & 0.9 & $-2.21-0.54$ & $0.2229^{\mathrm{a}}$ \\
\hline Weight $[\mathrm{kg}]$ & $71.5 \pm 11.6$ & $45-98$ & $71.4 \pm 12.1$ & $42-101$ & 0.1 & $-2.81-2.48$ & $0.9069^{\mathrm{a}}$ \\
\hline Height $[\mathrm{cm}]$ & $163.6 \pm 5.29$ & $144-175$ & $164.5 \pm 4.61$ & $153-174$ & 0.9 & $-0.22-1.98$ & $0.1188^{\mathrm{a}}$ \\
\hline BMI & $26.7 \pm 4.71$ & $17.8-39.7$ & $26.2 \pm 4.46$ & $17.2-38.3$ & 0.5 & $-1.45-0.59$ & $0.4079^{\mathrm{a}}$ \\
\hline \multicolumn{8}{|l|}{ Workers [\%] } \\
\hline white-collar & $44 \pm 28$ & & $42 \pm 27$ & & 2 & & $0.9732^{\mathrm{b}}$ \\
\hline pink-collar & $57 \pm 36$ & & $59 \pm 38$ & & 2 & & \\
\hline blue-collar & $56 \pm 36$ & & $54 \pm 35$ & & 2 & & \\
\hline Work experience [years] & $24.9 \pm 6.54$ & $9-40$ & $26.12 \pm 5.31$ & $11-39$ & 1.22 & $-3.12-0.35$ & $0.0824^{\mathrm{a}}$ \\
\hline Working week $[\mathrm{h}]$ & $39.2 \pm 1.65$ & $35-40$ & $39.9 \pm 1.77$ & $38-42$ & 0.7 & $-0.54-0.38$ & $0.6234^{\mathrm{a}}$ \\
\hline
\end{tabular}

CTS - carpal tunnel syndrome.

${ }^{\text {a }}$ Student's t-test; ${ }^{\text {b }}$ Chi-square test. 
- diminished nerve conduction values $(<50 \mathrm{~m} / \mathrm{s})$ and/or increased motor latency $(>4 \mathrm{~m} / \mathrm{s})$ in a nerve conduction study (NCS);

- presence of $\geq 2$ of the following positive symptoms [32]: 1) numbness and tingling in the area of the median nerve; 2) night-time paraesthesia; 3) positive Phalen's test; 4) positive Tinel's sign; 5) pain in the wrist area radiating to the shoulder;

- a score of 1-3 on the Hi-Ob Scale, which confirms mild and moderate forms of CTS [33].

Inclusion criteria for professionally active healthy women in the control group were:

- good general health,

- consent to participate in the research,

- lack of symptoms listed above in 1-5 for CTS patients.

Exclusion criteria for women in both groups were: previous surgical treatment, current steroid or non-steroid pharmacotherapy, cervical radiculopathy, tendon sheath inflammation, rheumatoid diseases, diabetes, pregnancy, past trauma to the wrist and muscular atrophy of the thenar eminence.

\section{Measures}

In the case study group, NCS were performed in an electromyography (EMG) laboratory. Nerve conduction values $\geq 50 \mathrm{~m} / \mathrm{s}$ were considered normal. Distal motor latency was calculated from motor fibers (values $\leq 4 \mathrm{~m} / \mathrm{s}$ were considered normal). Symptom severity (SSS - symptom severity scale) and physical capacity (FSS - functional status scale) were evaluated using the Boston Carpal Tunnel Questionnaire (BCTQ) [34]. Pain was evaluated using the Numerical Pain Rating Scale (NPRS) (0 - no pain, 10 - maximum pain) [35].

In both groups, the examination of static 2-point discrimination sense (2PD) was performed using a standardized Dellon discriminator (Baseline Discrim-A-Gon Discriminator). Prior to the measurements, the protocol was explained to the participants. The discriminator pins were applied perpendicularly to the long axis of the distal phalanges of fingers I, II and III. The discriminator was placed on the skin with enough pressure to cause stimulation but no pain. The contact time of the discriminator with the fingertip ranged 3-5 s. The fingertip was randomly touched with 1 or 2 spikes of the discriminator and during that time the participant was asked to say "one" if she felt 1 point or "two" if she felt 2 points. The smallest distance the participant recognized as a sensation of 2 points was recorded in millimeters and used for analysis [36]. The measurement was done 3 times and the mean value was taken into the analysis.

The force of the cylindrical grip and the pinch grip were evaluated [37] using the Jamara hydraulic dynamometer. The assessment was done in a sitting position. To judge the cylindrical grip, the dynamometer was positioned between the metacarpus and fingers II-V. When assessing pinch grip strength, the dynamometer was placed between the thumb and the lateral surface of the index finger. The values were in kilograms of strength $(\mathrm{kg})$. The measurement was done 3 times and the mean value was taken into the analysis.

To assess the amount of error in the kinesthetic differentiation of strength (KDS) in cylindrical and pinch grips, the maximum strength was measured as well as $50 \%$ of maximum strength. The measurement was also performed 3 times in this test and for further analysis the average value was taken. The examination of maximum strength and the $50 \%$ of maximum strength allowed the calculation of the error made by the subject. For this purpose, the following formula was used [25]:

$$
\frac{50 \% \text { MS-RMMS }}{50 \% \mathrm{MS}} \times 100=\%
$$

where:

$50 \%$ MS $-50 \%$ of maximum strength value,

RMMS - the real measure obtained during the measurement of $50 \%$ of the maximum strength. 
The range of motion (ROM) of flexion and extension of the radiocarpal joint was measured using a digital Saunders inclinometer. The tests were performed in a sitting position; the participant's upper limb was positioned neutrally at the shoulder, bent to an angle of $90^{\circ}$ at the elbow with the forearm in pronation. The forearm rested on a therapeutic table and the radiocarpal joint was set in neutral (parallel to the table) position. The hand was positioned outside the table with the palmar side facing towards the ground. In the assessment of flexion and extension movements the inclinometer was applied on the dorsal side of the hand parallel to the third metacarpal bone and middle finger. Measurements of the maximum of the active ROM of extension and flexion were carried out 3 times, and for further analysis, the average value was taken.

To assess the amount of error in the kinesthetic differentiation of movement (KDM) in flexion and extension of the radiocarpal joint, the maximum ROM was measured as well as $50 \%$ of maximum ROM. The measurement was also performed 3 times in this test and, for further analysis, the average value was taken. The examination of maximum ROM and the $50 \%$ of maximum ROM allowed calculation of the error made by the subject. For this purpose, the following formula was used [38]:

$$
\frac{50 \% \text { ROM-RMROM }}{50 \% \text { ROM }} \times 100=\%
$$

where:

$50 \%$ ROM $-50 \%$ of maximum range of motion value, RMROM - the real measure obtained during the measurement of $50 \%$ of the maximum strength.

\section{Statistical analysis}

All the obtained results were statistically analyzed. Homogeneity of variance for each variable was checked by using Levene's test. Next, variables were analyzed by using the t-test for independent samples. The paper presents mean values (mean values of differences), standard deviations
(SD) and 95\% confidence intervals $(95 \% \mathrm{CI})$. The critical p level was set at 0.05 .

\section{RESULTS}

Studies have shown that in professionally active women with CTS, mean sensory conduction was $\bar{x}=32.4 \mathrm{~m} / \mathrm{s}$, $\mathrm{SD}=13.8$ and this was reduced from the normal values (normal values $\geq 50 \mathrm{~m} / \mathrm{s}$ ). The mean motor conduction velocity was $\bar{x}=55.1 \mathrm{~m} / \mathrm{s}, \mathrm{SD}=6.2$ and this was not reduced from the normal values (normal values $\geq 50 \mathrm{~m} / \mathrm{s}$ ). Mean terminal latency of the median nerve was $\bar{x}=5.51 \mathrm{~m} / \mathrm{s}$, $\mathrm{SD}=1.1$ (normal values $\leq 4)$. Mean symptom severity (SSS) was $\overline{\mathrm{x}}=2.97, \mathrm{SD}=0.63(\max 5)$ and physical capacity (FSS) was $\bar{x}=2.81, S D=0.69(\max 5)$. Mean pain score was $\bar{x}=5.72, \mathrm{SD}=1.49(\max 10)$.

The Table 2 shows the evaluation of 2PD sensation in both groups. In all cases, the 2PD sensation was higher in women with CTS than in healthy women. Strength and KDS were significantly lower in women with CTS compared to healthy ones (Table 3 ). There were no differences between the groups in ROM, but there were significant differences in the case of KDM (Table 4).

\section{DISCUSSION}

The main purpose of this study was to assess manual dysfunction in occupationally active women with CTS. The results of this study demonstrate that active women have significantly lower manual skills, already in mild and moderate CTS, due to multiple sensory and muscle strength disorders. The 2PD sense in the case of women with CTS was on average up to $144 \%$ higher compared to healthy women. The strength of the muscles responsible for the cylindrical grip decreased on average by $14 \%$ in the case of women with CTS and the strength of the muscles responsible for the pincer grip by $10 \%$ compared to healthy women. The kinesthetic differentiation of strength discrepancies was much more significant than the strength ones. In KDS, the difference between women with CTS 
Table 2. Two-point discrimination on fingertips (finger I-III) in professionally active women with carpal tunnel syndrome (CTS) from southern Poland

\begin{tabular}{|c|c|c|c|c|c|c|}
\hline \multirow{3}{*}{ Two-point discrimination } & \multicolumn{4}{|c|}{ Respondents } & \multirow{3}{*}{ Difference $(95 \% \mathrm{CI})$} & \multirow{3}{*}{$\mathrm{p}^{\mathrm{a}}$} \\
\hline & \multicolumn{2}{|c|}{ CTS } & \multicolumn{2}{|c|}{ control } & & \\
\hline & $\mathrm{M} \pm \mathrm{SD}$ & $\min .-\max$ & $\mathrm{M} \pm \mathrm{SD}$ & $\min .-\max$ & & \\
\hline \multicolumn{7}{|l|}{$\begin{array}{l}\text { Right hand (CTS: } \mathrm{N}=157 \text {, } \\
\text { control: } \mathrm{N}=155)[\mathrm{mm}]\end{array}$} \\
\hline finger I & $5.36 \pm 1.69$ & $3-10$ & $2.23 \pm 0.57$ & $2-5$ & $3.13(-3.41-(-2.84))$ & $<0.001^{*}$ \\
\hline finger II & $5.11 \pm 1.55$ & $3-8$ & $2.26 \pm 0.54$ & $2-5$ & $2.85(-3.11-(-2.59))$ & $<0.001^{*}$ \\
\hline finger III & $4.41 \pm 1.41$ & $3-8$ & $2.21 \pm 0.47$ & $2-4$ & $2.2(-2.44-(-1.97))$ & $<0.001^{*}$ \\
\hline \multicolumn{7}{|l|}{$\begin{array}{l}\text { Left hand (CTS: } \mathrm{N}=50 \\
\quad \text { control: } \mathrm{N}=155)[\mathrm{mm}]\end{array}$} \\
\hline finger I & $5.42 \pm 1.32$ & $3-7$ & $2.19 \pm 0.52$ & $2-5$ & $3.23(-3.48-(-2.97))$ & $<0.001^{*}$ \\
\hline finger II & $6.21 \pm 1.48$ & $4-8$ & $2.21 \pm 0.47$ & $2-4$ & $4.0(-4.24-(-3.71))$ & $<0.001^{*}$ \\
\hline finger III & $5.94 \pm 1.47$ & $3-8$ & $2.21 \pm 0.51$ & $2-4$ & $3.73(-3.99-(-3.44))$ & $<0.001^{*}$ \\
\hline
\end{tabular}

a T-test result for independent samples.

* Statistically significant difference.

Table 3. Strength and kinesthetic differentiation of strength (KDS) of pincer and cylindrical grips in professionally active women with carpal tunnel syndrome (CTS) from southern Poland

\begin{tabular}{|c|c|c|c|c|c|c|}
\hline \multirow{3}{*}{ Grip } & \multicolumn{4}{|c|}{ Respondents } & \multirow{3}{*}{ Difference $(95 \%$ CI) } & \multirow{3}{*}{$\mathrm{p}^{\mathrm{a}}$} \\
\hline & \multicolumn{2}{|c|}{ CTS } & \multicolumn{2}{|c|}{ control } & & \\
\hline & $\mathrm{M} \pm \mathrm{SD}$ & $\min .-\max$ & $\mathrm{M} \pm \mathrm{SD}$ & $\min .-\max$ & & \\
\hline \multirow{2}{*}{\multicolumn{7}{|c|}{$\begin{array}{l}\text { Right hand (CTS: } \mathrm{N}=157 \text {, } \\
\text { control: } \mathrm{N}=155) \\
\text { pincer grip }\end{array}$}} \\
\hline & & & & & & \\
\hline strength $[\mathrm{kg}]$ & $5.97 \pm 1.44$ & $2-9$ & $6.43 \pm 1.23$ & $4-13$ & $0.46(0.16-0.74)$ & $<0.002 *$ \\
\hline$\%$ error & $30.7 \pm 20.5$ & $10.3-86.6$ & $17.9 \pm 13.8$ & $0.0-33.3$ & $12.8(-16.6-(-8.95))$ & $<0.001^{*}$ \\
\hline \multicolumn{7}{|l|}{ cylindrical grip } \\
\hline strength [kg] & $22.5 \pm 7.11$ & 8-37 & $25.8 \pm 5.27$ & $15-41$ & $3.33(2.03-4.75)$ & $<0.001^{*}$ \\
\hline$\%$ error & $31.6 \pm 16.5$ & $9.01-92.5$ & $13.8 \pm 11.5$ & $0.0-25$ & $17.8(-20.8-(-14.6))$ & $<0.001^{*}$ \\
\hline \multirow{2}{*}{\multicolumn{7}{|c|}{$\begin{array}{l}\text { Left hand (CTS: } \mathrm{N}=50 \text {, } \\
\text { control: } \mathrm{N}=155) \\
\text { pincer grip }\end{array}$}} \\
\hline & & & & & & \\
\hline strength $[\mathrm{kg}]$ & $5.52 \pm 1.91$ & $2-8$ & $6.17 \pm 1.54$ & $3-9$ & $0.65(0.12-1.17)$ & $<0.015^{*}$ \\
\hline$\%$ error & $27.8 \pm 11.4$ & $14.1-55.2$ & $17.1 \pm 12.1$ & $0.0-31$ & $10.7(-14.6-(-7.02))$ & $<0.001^{*}$ \\
\hline \multicolumn{7}{|l|}{ cylindrical grip } \\
\hline strength $[\mathrm{kg}]$ & $21.14 \pm 9.13$ & $8-33$ & $24.1 \pm 5.34$ & $12-40$ & $2.96(0.84-4.99)$ & $<0.001^{*}$ \\
\hline$\%$ error & $29.4 \pm 16.7$ & $10.3-68.4$ & $13.7 \pm 9.44$ & $0.0-28$ & $15.7(-19.43-(-11.96))$ & $<0.001 *$ \\
\hline
\end{tabular}

${ }^{a}$ T-test result for independent samples.

* Statistically significant difference. 
Table 4. Range of motion (ROM) and kinesthetic differentiation of movement (KDM) in the radiocarpal joints in professionally active women with carpal tunnel syndrome (CTS) from southern Poland

\begin{tabular}{|c|c|c|c|c|c|c|}
\hline \multirow{3}{*}{ Hand } & \multicolumn{4}{|c|}{ Respondents } & \multirow{3}{*}{ Difference $(95 \% \mathrm{CI})$} & \multirow{3}{*}{$\mathrm{p}^{\mathrm{a}}$} \\
\hline & \multicolumn{2}{|c|}{ CTS } & \multicolumn{2}{|c|}{ control } & & \\
\hline & $\mathrm{M} \pm \mathrm{SD}$ & $\min .-\max$ & $\mathrm{M} \pm \mathrm{SD}$ & $\min .-\max$ & & \\
\hline \multirow{2}{*}{\multicolumn{7}{|c|}{$\begin{array}{l}\text { Right (CTS: } \mathrm{N}=157 \text {, } \\
\text { control: } \mathrm{N}=155 \text { ) } \\
\text { extension }\end{array}$}} \\
\hline & & & & & & \\
\hline ROM & $62.6 \pm 12.3$ & $30-88$ & $62.8 \pm 7.71$ & $45-84$ & $0.2(-0.43-3.53)$ & $<0.097$ \\
\hline$\%$ error & $21.6 \pm 7.91$ & $16.5-38.6$ & $16.6 \pm 12.5$ & $0.0-48.2$ & $5.0(-12.3-(-7.54))$ & $<0.001^{*}$ \\
\hline \multicolumn{7}{|l|}{ flexion } \\
\hline ROM & $71.6 \pm 10.2$ & $44-92$ & $73.1 \pm 7.92$ & $49-96$ & $1.5(-2.13-2.35)$ & $<0.125$ \\
\hline$\%$ error & $25.9 \pm 9.5$ & $10.4-55.9$ & $16.1 \pm 12.9$ & $0.0-44$ & $9.8(-10.8-(-4.92))$ & $<0.001^{*}$ \\
\hline \multicolumn{7}{|c|}{$\begin{array}{r}\text { Left }(\mathrm{CTS}: \mathrm{N}=50 \\
\quad \text { control: } \mathrm{N}=155)\end{array}$} \\
\hline \multicolumn{7}{|c|}{ extension } \\
\hline ROM & $62.7 \pm 6.31$ & $55-85$ & $61.8 \pm 6.71$ & $42-80$ & $0.9(-3.14-2.21)$ & $<0.922$ \\
\hline$\%$ error & $22.7 \pm 6.89$ & $15.4-34.1$ & $15.3 \pm 12.5$ & $0.0-38.2$ & $7.4(-15.1-(-6.53))$ & $<0.001^{*}$ \\
\hline \multicolumn{7}{|l|}{ flexion } \\
\hline ROM & $71.8 \pm 8.32$ & $65-90$ & $71.3 \pm 8.34$ & $51-93$ & $0.5(-3.04-1.21)$ & $<0.729$ \\
\hline$\%$ error & $28.3 \pm 6.67$ & $14.2-44.1$ & $17.5 \pm 14.7$ & $0.0-35$ & $10.8(-10.9-(-3.62))$ & $<0.001^{*}$ \\
\hline
\end{tabular}

a T-test result for independent samples.

* Statistically significant difference.

and healthy women, in the mean bias error, was $122 \%$ for cylindrical grip and $67 \%$ for pincer grip. There were no significant differences in mobility of the radiocarpal joint between women with CTS and healthy women, although KDM was significantly impaired. In KDM, the difference between women with CTS and healthy women, in the mean bias error, was $39 \%$ and $61 \%$ for extension and flexion, respectively.

Diverse sensation disorder types in the general population of occupationally active people with CTS were studied by Wolny et al. [26]. The authors identified significant disorders of 2PD sense, KDS in cylindrical and pincer grips, and KDM in flexion and extension of the radiocarpal joint, as compared to healthy subjects for the dominant right hand. The results of the studies concerning occupationally active women with CTS have shown incidence of similar disorders in symptomatic hands, in both one-sided and bilateral CTS.

Many authors have investigated 2PD sense in individuals with CTS [26,27,39]. The 2PD sense test is a simple and reliable way of evaluating astereognosis [36,40] and moreover, the relationship between 2PD sense and hand function has been proven [41]. Worse 2PD sense results in a deterioration of hand function, which is important in the non-occupational activities of the day, as well as in the workplace [41]. Impairment of 2PD sense due to astereognosis may also increase the risk of hand injuries which are among the most common occupational accidents [37]. Deterioration of 2PD sense in occupationally active women with CTS, as previously reported [41], leads to impairment not only of exteroceptive sensation, but also proprioceptive sensation [25], which, already in the 
early stages, reduces the functional capacity of the hand and may have occupational consequences in the form of reduced productivity.

The muscle strength in cylindrical and pincer grips has also been frequently assessed in CTS patients [27,30,39], as it is an important component, which influences the manual capacity of the hand, especially in those occupations which require greater muscle strength (cylindrical grip) and/or greater movement precision (pincer grip) during occupational activities. It is obvious that the weakening of muscle strength and hence the weakening of the grip, must result in less functional efficiency of the hand and thus, less productivity. Decrease in muscle strength, which our study demonstrates, was significant, but not as large (10-14\%) as the disturbance of other tested parameters. Some authors report that in mild and moderate CTS, muscle strength is not yet impaired and only further progression of the disease leads to muscle weakness and atrophy [42]. However, one should remember that CTS is also associated with other symptoms that can affect muscle strength. Weakening of muscle strength demonstrated in our experiment may be a result of the pain experienced by the subjects, which does not allow them to use full muscle strength [43].

Although muscle strength was less disturbed, the successive results of our studies show that KDS in both mild and moderate forms of CTS is significantly impaired in both the cylindrical and pincer grips. The KDS used is an essential component of the functional efficiency of the hand, so its impairment can result in decreased precision of movement and thereby, reduce the functional efficiency of the hand, which causes a deterioration in productivity. Also in this case, the kinesthetic differentiation disorder may be attributable to pain, which is a major symptom of CTS, since, as indicated by Tamburin et al. [43] pain may impair motor control and thus, interfere with proper motor performance.

The range of motion of the radiocarpal joint was not significantly different between women with CTS and healthy women, and was within the normal range. Moreover, the mean values obtained in the measurements did not differ significantly from those of the general population [38], which suggests that CTS has little effect on the ROM of the radiocarpal joint. Similar values for ROM were also obtained in the studies by Mohamed et al. [44], while Tal-Akabi and Rushton presented smaller ROM in CTS subjects [28]. Tal-Akabi and Rushton's study could be influenced by a small number of participants (only 21) and age (29-85 years). Especially in older people, degenerative changes in radiocarpal joints may have contributed to the limitation of ROM and due to such a small number of subjects, to the average for the whole group.

Significant disturbances also occurred in KDM of women with CTS, as compared to healthy women. The results obtained in this experiment are even slightly worse than in a general population study of subjects with CTS [38]. Kinesthetic differentiation of movement is an important parameter affecting the functional efficiency of the hand and its impairment can significantly reduce the function of the hand in day-to-day activities, occupational and non-occupational. This may be particularly important in occupations that require high precision of movement. It may impair both the planning process of a motion activity, as well as its performance, which may affect functional capacity and decrease productivity. One of the factors affecting KDM disorders (similar to KDS) may be pain associated with CTS [43].

Disturbances of the various sensation types that occur in women with CTS may, to some extent, be compensated for by the sight organ, especially when it comes to proprioceptive (including kinesthetic) sensation. In addition, one of the elements of compensation may also be an increase in muscle tone, as well as a change in the strategy of the motion activity performed. It seems, however, that such solutions, overall, must adversely affect various areas of the motor system, which may aggravate both the symptoms of CTS as well as cause overload and degenerative 
changes in distant locations. The consequence of this is the deteriorating quality of health on the one hand and, on the other, lower productivity and increased absence from work, which has a significant economic and social dimension due to the enormous costs of treatment and reduced productivity.

The limitations of this study are primarily the large occupational diversity of the women with CTS. The multitude of occupations of today, the variety of activities performed sometimes in the same position and different workloads, make it difficult to choose a homogeneous group. Therefore, the study included women in 3 groups: white-, pinkand blue-collar workers, who reported high engagement of their hands at work. Another limitation is that there is no NCS study of healthy subjects and therefore, there is no certainty that the control group was free of people with other medical conditions, although the inclusion criteria included participation conditions such as good general health and lack of CTS symptoms, thus the probability that there was any pathology is much smaller.

So far, the literature has lacked a comprehensive assessment of distinct sensation types (exteroceptive, proprioceptive), KDS and KDM, as well as strength and ROM scores in occupationally active women with CTS, which is a strong side of this study. In addition, the study included numerous subjects. Moreover, the inclusion criteria that involved the physician posting a diagnosis based on NCS and clinical judgement are strengths of this study. The use of reliable measuring tools also raises the value of the study and allows error minimization.

In summary, it should be stressed that the disturbances of different sensation types and the reduction of muscle strength in occupationally active women with CTS must reduce the functional capacity of the hand, and the resulting consequences relate to many aspects of occupational and non-occupational life, as well as economic and social costs. Therefore, in the case of occupationally active women with CTS, it is necessary to diagnose the disease quickly and seek immediate and effective therapy. If the cause of CTS is the occupational activity, it may be necessary to quickly change the workplace so as not to aggravate existing problems.

\section{CONCLUSIONS}

The results obtained in our research indicate that in professionally active women with CTS, there are disorders of manual capacity that result from impairment of different sensation types (2PD sense, KDS, KDM) and muscle weakness. Carpal tunnel syndrome does not limit the $\mathrm{ROM}$ of the radiocarpal joint in occupationally active women with CTS, as compared to healthy women.

\section{REFERENCES}

1. Aroori S, Spence RA. Carpal tunnel syndrome. Ulster Med J. 2008;77(1):6-17.

2. Lewańska M, Wągrowska-Koski E, Walusiak-Skorupa J. [Etiological factors for developing carpal tunnel syndrome in people who work with computers]. Med Pr. 2013;64(1):37-45, http:// doi.org/10.13075/mp.5893/2013/0005. Polish.

3. Atroshi I, Gummesson C, Johnsson R, Ornstein E, Ranstam J, Rosén I. Prevalence of carpal tunnel syndrome in a general population. JAMA. 1999;282(2):153-8, http://doi.org/10. 1001/jama.282.2.153.

4. De Krom MC, Knipschild PG, Kester AD, Thijs CT, Boekkooi PF, Spaans F. Carpal tunnel syndrome: Prevalence in the general population. J Clin Epidemiol. 1992;45(4):373-6, http://doi.org/10.1016/0895-4356(92)90038-O.

5. Tanaka S, Wild DK, Seligman PJ, Behrens V, Cameron L, Putz-Anderson V. The US prevalence of self-reported carpal tunnel syndrome: 1988 National Health Interview Survey data. Am J Public Health. 1994;84(11):1846-8, http://doi.org/ 10.2105/AJPH.84.11.1846.

6. Barnhart S, Demers PA, Miller M, Longstreth WT Jr, Rosenstock L. Carpal tunnel syndrome among ski manufacturing workers. Scand J Work Environ Health. 1991;17(1):46-52, https://doi.org/10.5271/sjweh.1735. 
7. Atterbury MR, Limke JC, Lemasters GK, Li Y, Forrester C, Stinson R, et al. Nested case-control study of hand and wrist work-related musculoskeletal disorders in carpenters. Am J Ind Med. 1996;30(6):695-701.

8. Geoghegan JM, Clark DI, Bainbridge LC, Smith C, Hubbard R. Risk factors in carpal tunnel syndrome. J Hand Surg Br. 2004;29(4):315-20, http://doi.org/10.1016/j.jhsb. 2004.02.009.

9. Bland JD, Rudolfer SM. Clinical surveillance of carpal tunnel syndrome in two areas of the United Kingdom, 19912001. J Neurol Neurosurg Psychiatry. 2003;74(12):1674-9, http://doi.org/10.1136/jnnp.74.12.1674.

10. Bongers FJ, Schellevis FG, van den Bosch WJ, van der Zee J. Carpal tunnel syndrome in general practice (1987 and 2001): Incidence and the role of occupational and non-occupational factors. Br J Gen Pract. 2007;57(534):36-9.

11. Padua L, Coraci D, Erra C, Pazzaglia C, Paolasso I, Loreti C, et al. Carpal tunnel syndrome: Clinical features, diagnosis, and management. Lancet Neurol. 2016;15(12):1273-84, http://doi.org/10.1016/S1474-4422(16)30231-9.

12. Bonfiglioli R, Mattioli S, Fiorentini C, Graziosi F, Curti S, Violante FS. Relationship between repetitive work and the prevalence of carpal tunnel syndrome in part-time and fulltime female supermarket cashiers: A quasi-experimental study. Int Arch Occup Environ Health. 2007;80(3):248-53, http://doi.org/10.1007/s00420-006-0129-0.

13. Cannon LJ, Bernacki EJ, Walter SD. Personal and occupational factors associated with carpal tunnel syndrome. J Occup Med. 1981;23(4):255-8.

14. Silverstein BA, Fine LJ, Armstrong TJ. Occupational factors and carpal tunnel syndrome. Am J Ind Med. 1987;11(3):34358, https://doi.org/10.1002/ajim.4700110310.

15. De Krom MC, Kester AD, Knipschild PG, Spaans F. Risk factors for carpal tunnel syndrome. Am J Epidemiol. 1990;132(6):1102-10, https://doi.org/10.1093/oxfordjournals. aje.a115753.

16. Wieslander G, Norbäck D, Göthe CJ, Juhlin L. Carpal tunnel syndrome (CTS) and exposure to vibration, repetitive wrist movements, and heavy manual work: A case-referent study. Br J Ind Med. 1989;46(1):43-7, https://doi.org/10.1136/oem. 46.1.43.

17. Chiang HC, Chen SS, Yu HS, Ko YC. The occurrence of carpal tunnel syndrome in frozen food factory employees. Gaoxiong Yi Xue Ke Xue Za Zhi. 1990;6(2):73-80.

18. Osorio AM, Ames RG, Jones J, Castorina J, Rempel D, Estrin W, et al. Carpal tunnel syndrome among grocery store workers. Am J Ind Med. 1994;25(2):229-45, http://doi. org/10.1002/ajim.4700250209.

19. Margolis W, Kraus JF. The prevalence of carpal tunnel syndrome symptoms in female supermarket checkers. J Occup Med. 1987;29(12):953-6.

20. Isolani L, Bonfiglioli R, Raffi GB, Violante FS. Different case definitions to describe the prevalence of occupational carpal tunnel syndrome in meat industry workers. Int Arch Occup Environ Health. 2002;75(4):229-34, http://doi. org/10.1007/s00420-001-0304-2.

21. Riccò M, Signorelli C. Personal and occupational risk factors for carpal tunnel syndrome in meat processing industry workers in Northern Italy. Med Pr. 2017;68(2):199-209, http://doi.org/10.13075/mp.5893.00605.

22. Mondelli M, Grippo A, Mariani M, Baldasseroni A, Ansuini R, Ballerini $\mathrm{M}$, et al. Carpal tunnel syndrome and ulnar neuropathy at the elbow in floor cleaners. Neurophysiol Clin. 2006; 36(4):245-53, http://doi.org/10.1016/j.neucli.2006.08.013.

23. McDiarmid M, Oliver M, Ruser J, Gucer P. Male and female rate differences in carpal tunnel syndrome injuries: Personal attributes or job tasks? Environ Res. 2000;83(1):23-32, http://doi.org/10.1006/enrs.2000.4042.

24. Messing K, Chatigny C, Courville J. "Light" and "heavy" work in the housekeeping service of a hospital. Appl Ergon. 1998;29(6):451-9, http://doi.org/10.1016/S0003-6870(98) 00013-1.

25. Wolny T, Saulicz E, Linek P, Myśliwiec A. Two-point discrimination and kinesthetic sense disorders in productive age individuals with carpal tunnel syndrome. J Occup Health. 2016;58(3):289-96, http://doi.org/10.1539/joh.15-0108-OA. 
26. Wolny T, Saulicz E, Linek P, Myśliwiec A. [Kinesthesia of force and motion and the tactile discrimination in patients with a mild form of carpal tunnel syndrome]. Phys Med Rehab Kuror. 2015;25(2):101-7, http://doi.org/10.1055/s-0034-13 98669. German.

27. Akalin E, El O, Peker O, Senocak O, Tamci S, Gülbahar S, et al. Treatment of carpal tunnel syndrome with nerve and tendon gliding exercises. Am J Phys Med Rehabil. 2002;81(2): 108-13, https://doi.org/10.1097/00002060-200202000-00006.

28. Tal-Akabi A, Rushton A. An investigation to compare the effectiveness of carpal bone mobilisation and neurodynamic mobilisation as methods of treatment for carpal tunnel syndrome. Man Ther. 2000;5(4):214-22, http://doi.org/10.1054/ math.2000.0355.

29. Wolny T, Saulicz E, Linek P, Shacklock M, Myśliwiec A. Efficacy of manual therapy including neurodynamic techniques for the treatment of carpal tunnel syndrome: A randomized controlled trial. J Manipulative Physiol Ther. 2017;40(4): 263-72, http://doi.org/10.1016/j.jmpt.2017.02.004.

30. Brininger TL, Rogers JC, Holm MB, Baker NA, Li ZM, Goitz RJ. Efficacy of a fabricated customized splint and tendon and nerve gliding exercises for the treatment of carpal tunnel syndrome: A randomized controlled trial. Arch Phys Med Rehabil. 2007;88(11):1429-35, http://doi.org/10.1016/ j.apmr.2007.07.019.

31. Wolny T, Linek P, Saulicz E. Overall health status in patients with mild to moderate carpal tunnel syndrome: A casecontrol study. J Hand Ther. 2017;30(3)293-8, http://doi.org/ 10.1016/j.jht.2016.10.003.

32. Chang WD, Wu JH, Jiang JA, Yeh CY, Tsai CT. Carpal tunnel syndrome treated with a diode laser: A controlled treatment of the transverse carpal ligament. Photomed Laser Surg. 2008;26(6):551-7, http://doi.org/10.1089/pho.2007.2234.

33. Giannini F, Cioni R, Mondelli M, Padua R, Gregori B, D'Amico P, et al. A new clinical scale of carpal tunnel syndrome: Validation of the measurement and clinical-neurophysiological assessment. Clin Neuropsyhol. 2002;113(1):717, https://doi.org/10.1016/S1388-2457(01)00704-0.
34. Levine DW, Simmons BP, Koris MJ, Daltroy LH, Hohl GG, Fossel AH, et al. A self-administered questionnaire for the assessment of severity of symptoms and functional status in carpal tunnel syndrome. J Bone Joint Surg Am. 1993;75(11): 1585-92, https://doi.org/10.2106/00004623-199311000-00002.

35. Jensen MP, Turner JA, Romano JM, Fisher LD. Comparative reliability and validity of chronic pain intensity measures. Pain. 1999;83(2):157-62, http://doi.org/10.1016/s03043959(99)00101-3.

36. Wolny T, Linek P, Michalski P. Inter-rater reliability of two point discrimination in acute stroke patients. NeuroRehabilitation. 2017;41(1):127-34, http://doi.org/10.3233/NRE171464.

37. Watanabe T, Owashi K, Kanauchi Y, Mura N, Takahara M, Ogino T. The short-term reliability of grip strength measurement and the effects of posture and grip span. J Hand Surg Am. 2005;30(3):603-9, http://doi.org/10.1016/j.jhsa.2004. 12.007 .

38. Wolny T, Saulicz E, Linek P, Mysliwiec A, Zajac A. The influence of physiotherapy on the range of motion and kinesthetic sensation of movement in the radiocarpal articulation in patients with carpal tunnel syndrome. J Nov Physiother. 2015;5(2):251, http://doi.org/10.4172/2165-7025.1000251.

39. Pinar L, Enhos A, Ada S, Güngör N. Can we use nerve gliding exercises in women with carpal tunnel syndrome? Adv Ther. 2005;22(5):467-75, http://doi.org/10.1007/BF02849867.

40. Shooter D. Use of two-point discrimination as a nerve repair assessment tool: Preliminary report. ANZ J Surg. 2005;75(10):866-8, http://doi.org/10.1111/j.1445-2197.2005. 03557.x.

41. Novak CB, Mackinnon SE, Kelly L. Correlation of twopoint discrimination and hand function following median nerve injury. Ann Plast Surg. 1993;31(6):495-8, https://doi. org/10.1097/00000637-199312000-00003.

42. MacDermid JC, Doherty T. Clinical and electrodiagnostic testing of carpal tunnel syndrome: A narrative review. J Orthop Sports Phys Ther. 2004;34(10):565-88, http://doi. org/10.2519/jospt.2004.34.10.565. 
43. Tamburin S, Cacciatori C, Marani S, Zanette G. Pain and motor function in carpal tunnel syndrome: A clinical, neurophysiological and psychophysical study. J Neurol. 2008;255(11):1636-43, http://doi.org/10.1007/s00415-0080895-6.
44. Mohamed FI, Hassan AA, Abdel-Magied RA, Wageh RN. Manual therapy intervention in the treatment of patients with carpal tunnel syndrome: Median nerve mobilization versus medical treatment. Egypt Rheumatol Rehabil. 2016;43(1):27-34, http://doi.org/10.4103/1110-161X.177424.

This work is available in Open Access model and licensed under a Creative Commons Attribution-NonCommercial 3.0 Poland License - http://creativecommons.org/ licenses/by-nc/3.0/pl/deed.en. 